\title{
Early Mathematics Teaching Profiles
}

\author{
Bilge CEREZCI ${ }^{1}$
}

\begin{tabular}{lr} 
ARTICLE & \multicolumn{1}{l}{ INFO } \\
\hline Article ristory: & His.12.2018 \\
Received & 03.12 \\
Received in revised form \\
07.02 .2019 & \\
Accepted & \\
Available online 01.07 .2019
\end{tabular}

\begin{abstract}
Responding to the scarcity of research on early mathematics teaching profiles, this article reports on a novel assessment approach to identifying characteristics of early mathematics teaching occurring in early childhood settings. The new approach uses the interplay between teachers' content knowledge in mathematics, knowledge of students and learning, and knowledge of how to teach mathematics effectively during the course of early mathematics as a proxy to identify quality of mathematics instruction provided. In this study, 210 pre-kindergarten to 3rd grade teachers in a large public school system in the Midwest were observed as they taught mathematics. The descriptive results revealed that the quality of mathematics instruction varies considerably among early childhood teachers. Some teachers are identified as delivering high quality mathematics instruction because they provide students with opportunities to fully and purposefully engage in deepening their understanding of important mathematics concepts, whereas others are rated as far lower in quality, because their mathematics teaching is procedural in terms of content emphasized and instructional strategies used. As a whole, observed quality of mathematics teaching was revealed to be mediocre. Implications of results for early math professional development are discussed.
\end{abstract}

(C) IJERE. All rights reserved

Keywords:

Teaching Profession, Pedagogical Formation, Attitude.

Keywords:
Teaching Profession, Pedagogical Formation, Attitude.

\section{INTRODUCTION}

Growing evidence demonstrates that early mathematics teaching and learning experiences, among all educational resources, are especially important contributors to students' learning and later achievement in mathematics and other areas, particularly in low-SES students who are at risk of falling behind in mathematics achievement (Aunola, Leskinen, Lerkkanen, \& Nurmi, 2004; Carr \& Peters \& Young-Loveridge, 1994; Lee \& Ginsburg, 2009; NCMST, 2000; Sanders \& Rivers, 1996; Starkey, Klein, \& DeFlorio, 2014). As early mathematics education has assumed heightened importance, quality of early mathematics teaching and learning experiences has attracted national attention, and the pressure to perform in ma thematics has trickled down to preschoolers and kindergarteners. How can we provide our youngsters with the necessary skills and knowledge to succeed in math? The National Commission on Mathematics and Science Teaching for the 21st Century raises the same concern by asking a similar question: "As our children move tow ard the day when their decisions will be the ones shaping a new America, will they be equipped with the mathematical and scientific tools needed to meet those challenges and capitalize on those opportunities?" (NCMST, 2000, p.7).

\section{Mathematics Achievement}

Unfortunately, many students in the U.S. fail to master the foundational mathematical understanding in early elementary years and beyond (Romberg \& Kaput, 1999). In fact, "Since the 1970s, a series of assessments of U.S. students' performances has revealed an overall level of mathematical proficiency well below what is desired and needed" (National Association for the Education of Young Children and National Council of Teachers of Mathematics [NAEYC \& NCTM], 2002, p. 1). For example, the 2015 National Assessment of Educational Progress Report (NAEP) suggested that only $40 \%$ of a nationally representative sample of American students in 4th grade scored at or above a proficient level in mathematics achievement, and of those, $60 \%$ scored below proficient level. American children not only perform poorly on their own national mathematics tests, but they also lag behind their international peers mathematica lly. In the most recent Program for International Student Assessment (PISA) administered by the Organization

${ }^{1}$ Corresponding e-mail: cerezcib@stjohns.edu, https://orcid.org/0000-0002-9648-2387

St. John's University 
for Economic Cooperation and Development (OECD), the average math score of American 15-year-olds was 470, 94 points lower than the top performing country (Singapore), and 20 points lower than the OECD's average, positioning Americans 35th out of 72 participating countries (OECD, 2015). Both national and international assessment results again raise questions about the global competitiveness of the U.S. students' mathematics knowledge.

Mounting evidence indicates that the poor mathematics performance demonstrated by American students commences from the time of school entrance and the dependence of later school performance on the quality of early math experience (Aunola, Leskinen, Lerkkanen, \& Nurmi 2004; Carr \& Peters, 1995; Duncan, Dow sett, Cleassens, Huston, Pagani, Engel, Sexton et. al. 2007). For example, in a recent assessment of school readiness, by the Chicago Department of Children and Family Services, among 7,354 kindergartenage children attending Head Start programs in Chicago, 2,059 of them, or nearly one third, performed below the standard for school readiness in kindergarten mathematics based on the Teaching Standards GOLD Assessment System (Chicago DFSS, 2014). Furthermore, research also emphasizes the cumulative effects poor mathematics achievement by suggesting that if a student falls behind mathematically during the critical years of early schooling, it becomes increasingly unlikely that the student will catch up as she or he moves up the grade levels (Aunola, et. al., 2004; Bodovski \& Farkas, 2007; Flanagan, McPhee, \& Mulligan, 2009; Jordan, Kaplan, Ramineni, \& Lociniak, 2007;2009). Research also suggests that students who come from lowincome and minority groups are particularly at a higher risk of mathematics underachievement (Starkey, Klein, \& Wakeley, 2004). The gap between low and middle-income children includes a wide range of early mathematical areas, such as number sense, spatial sense and geometry, and measurement (Clements, Sarama, \& Gerber, 2005; Klein \& Starkey, 2004; Saxe, Guberman, \& Gearheart, 1987).

\section{Teachers and Mathematics Instruction}

Even though young children are natural mathematicians (NRC 2009) and capable of developing some complex mathematical ideas (e.g., addition) and strategies (e.g., sorting by multiple attributes to analyze data), it is also true that they do not become skilled in mathematics without intentional and high quality instruction (Baroody, 2001; Baroody \& Dowker, 2003; Clements, 2001; Epstein, 2003; Richardson \& Salkeld, 1995). For example, in an effort to assess the quality of mathematics teaching in U.S. classrooms and document how variations in quality of teaching might produce different student outcomes, Rivkin and colleagues (2005) collected and analyzed the math test scores of approximately one-half million students in grades 3 through 7 at over 3000 schools in Texas (Rivkin, Hanushek, \& Kain, 2005). In addition, specific demographic characteristics of teachers and schools (e.g., teacher experience, education, and class size) were also collected in order to estimate the quality of teaching. The researchers used matched data on teachers and students and made estimations in variations in teaching quality. Quality of instruction provided by the studied teachers was categorized as "low" or "high." The final report on this study suggested that students whose teachers provided high quality instruction gained 1.5 grade equivalents while students whose teachers provided low quality instruction only made a gain of 0.5 grade equivalents during the same academic year. Weiss and Pasley (2004) also emphasize the importance of high quality teaching in building foundations for future learning by stating that high quality teaching is more likely to engage students with important mathematics content and build on students' capacity to understand and implement these mathematics concepts.

Although research highlights the importance early math skills and their positive implications for later success and importance of providing intentional mathematics teaching and learning experiences, mathematics is often under-emphasized in early childhood settings. Observational studies of early childhood and early elementary revealed several reasons to why this is the case (Clements \& Sarama, 2011; Engel, Claessens, \& Finch, 2013). One line of research revealed that educators often do not allocate enough time for guided math learning experiences (Bargaglotti, Guarino, \& Mason, 2009; Chung, 1994; Rudd, 
Lambert, Satterwhite, \& Zaier, 2008). For example, Chung (1994) conducted a study to document the amount of time kindergarten teachers spent on teaching mathematics on a daily basis. Based on the observations gathered from 30 public school kindergarten teachers, Chung (1994) concluded that observed teachers spent about one fourth of their classroom time on teaching mathematics that was usually integrated with other learning activities, and that mathematics was seldom taught as a separate subject. In another study, Rudd and colleagues observed 11 teachers who worked with children ranging in age from birth to five years. Researchers gathered 40 hours of observations in which they noted no incidence that could be identified as intentionally planned mathematics activities (Rudd, Lambert, Satterwhite, \& Zaier, 2008). Similar trends has also observed in early elementary grades where teachers delivered mathematics instruction only 3 hours more per week compared to their preschool counterparts (Bargaglotti, et. al., 2009).

Another line of research indicated that most early childhood teachers underestimate what young children know and what they can learn in mathematics (Brown, 2005; Clements \& Sarama, 2009; Graham, Nash, \& Paul, 1997; Lee, 2004; Tudge \& Doucet, 2004; Van den Heuvel-Panhuizen, 1990). For example, in one study, Van den Heuvel-Panhuizen (1990) asked groups of preschool teachers and school staff who worked with preschoolers to estimate their preschoolers' mathematical competencies when they entered kindergarten the following year. Results of the study revealed that teachers and staff highly underestimated the math competencies of these young children. Particularly, when more than $80 \%$ of these kindergarteners were able to count out nine marbles, the adults' estimates only ranged between $20 \%$ and $50 \%$. Further, while more than $40 \%$ of these students were able to subtract 8 from 10 without using any manipulatives, adults estimated less than $10 \%$ of them would be capable of completing this task (Van den Heuvel-Panhuizen, 1990). This sort of underestimation often compromises what early childhood teachers teach and how they teach it (Brown, 2005; Graham, Nash, \& Paul, 1997; Lee, 2004; Tudge \& Doucet, 2004). Stated by Lee and Ginsburg, "Teachers often limit their focus to one-to-one correspondence, simple counting and numbers, and perhaps naming and sorting simple shapes, even when children are capable of learning far more complex content" $(2009$, p.39). While acquiring the basic skills in mathematics is important in early years, teachers need to help children build upon and extend them to deeper and broader mathematical concepts (Clements, 2004; Sarama \& Clements, 2010).

Last but not least, research has also revealed that, in the field of early education, most of the teachers do not possess the mathematical knowledge that is necessary to provide quality mathematics teaching and learning opportunities to young children (Ball, 1990; Ma, 1999; Hill, Schilling, \& Ball, 2004) and often do not feel confident in teaching them mathematics (Bursal \& Pazkanos, 2006; Copley, 2004; Wilkins, 2008). Teachers cannot teach what they do not know. Further discussing how teachers' content knowledge can affect the quality of their instructional practices, Brophy (1991) states that "Where (teacher's) knowledge is more explicit, better connected and more integrated, they will tend to teach the subject more dynamically, represent it more varied ways, and encourage and respond fully to student comments and questions. Where there knowledge is limited, they will tend to depend on the text content, de-emphasize interactive discourse in favor of seatwork assignments, and in general, portray the subject as a collection of static, factual knowledge." (Brophy, 1991, p.352)

Although the education system highly depends on the work and knowledge of early childhood teachers to help young children learn math concepts and develop math understanding, the same system does not put enough effort into equipping teachers with the necessary mathematics knowledge-base and skills that they require to undertake the task. Research indicates that most of the early childhood programs in higher education do not offer courses specifically devoted to mathematics teaching and learning in early childhood classrooms (Armstrong, Ginet, \& Warisi, 2012; Ginsburg, Lee, \& Stevenson, 2008; NRC, 2009). Even when they do, it usually does not exceed more than one course, which is not enough to equip prospective teachers with necessary domain specific knowledge in mathematics that they need in order to 
provide quality mathematics education for preschool and kindergarten children (Copple, 2004; Ginsburg et al., 2008; Ginsburg, Jang, Preston, VanEsselstyn, \& Appel, 2004).

\section{Situation of the Problem}

The research findings mentioned above point to the need for greater attention to early mathematics teaching practices and instruction as they can improve early mathematics education and yield long-term improvements in the skills and lives of the future generations. While it is clear that young children's performance in mathematics depends on their teachers' mathematical proficiency (Sarama, DiBiase, Clements, \& Spitler, 2004), we know little about what kind of mathematics teaching and learning experiences are provided by early childhood teachers. The limited association found between teacher and school characteristics and teacher effectiveness do not provide direct measures of instruction and leave the field with limited understanding of what is really happening in the course of mathemat ics teaching and learning. Thus, our limited understanding of teachers' mathematics instruction on early math teaching diminishes our ability to support teachers in the classroom and makes it difficult to meet their math professional development (PD) needs.

\section{Aim of the Study}

Responding to these gaps in the research literature, in this article we report on the findings of an observation measure that is specifically designed to unearth what kinds of early mathematics teaching profiles exist in early childhood classrooms. Given the importance of early mathematics skills for later school success, the research described in this article focuses on identifying the instructional in teractions in mathematics that effectively support young children's early mathematics skills development by examining quality of mathematics instruction during the course of mathematics teaching. Such research can add to the existing body of literature on mathematics teaching and offer insights for educational policy, teachers, teacher educators, and researchers regarding how to improve mathematics instruction and learning.

Quality of instruction and students' instructional experiences in early mathematics lay the foundation for the formal systems of math that will be taught later in school. Despite its importance, our knowledge about what constitutes effective instruction, how it looks in practice, and how to quantify it is quite limited (Ball \& Rowan, 2004; Brenneman, et. al., 2011). In order to address this gap in the literature, current study investigates the descriptive picture of early mathematics teaching profile that exists in pre-K to 3rd grade classrooms. Early mathematics instruction is documented, analyzed and assessed according to specific indicators in several areas: the quality of early mathematics content, the quality if implementation and the extent to which the instruction is facilitated developmentally appropriate learning experiences. Exam ining the quality of early mathematics instruction through these lenses may shed light on the characteristics of early childhood teachers' mathematics teaching and how to better support young children's developing mathematics understanding. The present study attempts investigate the following questions:

1. What is the profile of early mathematics teaching quality?

2. Are there different groups of teachers regarding the quality of instruction that they deliver? If so, what are the differences between teachers who deliver high quality mathematics teaching and learning experiences and teachers who do not?

\section{METHOD}

\section{Sample}

A total of 210 preschool to 3rd grade teachers from 16 schools in a large, urban, public school system in Midwest are observed. The number teachers from each school ranged from 6 to $18(M=13) .95 .7 \%$ of the participants were females and the majority $(60 \%)$ w as between 25 and 44 years old. There were about $54.3 \%$ $(n=114)$ teachers from each elementary grade and about $40.5 \%(n=85)$ teachers from Pre-K and Kindergarten respectively, and $5 \%$ of the sample $(\mathrm{n}=11)$ were working in mixed age classrooms (e.g., Kindergarten and 1st grade split). The number of years teachers had worked as teachers ranged from 1 to 41, with a mean of 
approximately 13 years. More than one quarter of the sample had been teaching for less than five years. About half of the sample identified themselves as Caucasian/White, one third of the sample was Hispanic/Latino, and one tenth was Black. All teachers were certified to teach and had varying degrees of professional development experiences in early mathematics. On average, teachers had participated in 9 hours of in-service math professional development (PD) prior to this study.

\section{Material}

Designed specifically for use in this study, High-Impact Strategies for Early Mathematics (HIS-EM) is a lesson-based observation tool that is designed to be used in preschool through 3rd grade classrooms in order to measure the quality of mathematics teaching (Early Math Collaborative, 2011). As an observation tool, HIS-EM focuses on the intentional instructional activities of a teacher; for that reason, the period of observation is from the start to the finish of a single teacher-directed mathematics lesson.

According to HIS-EM, the interplay between teachers' content knowledge in mathematics, knowledge of students and their learning, and knowledge of how to teach mathematics effectively during the course of early mathematics lessons can be observed and reflects the quality of mathematics instruction provided. In this model, the quality of mathematics instruction is determined by the degree to which the teacher helps children to interpret foundational mathematical principles conceptually and supports the development of their intuitive knowledge into robust and transferable knowledge in mathematical thinking with developmentally appropriate ways. HIS-EM categorizes indicators of quality of early mathematics teaching first according to three primary domains: (1) foundational knowledge of the mathematics (i.e., what); (2) understanding knowledge of young children's learning in mathematics (i.e., who); and (3) effective use of instructional support in mathematics (i.e., how). Three dimensions further define each domain. "What" domain is assessed through evaluation of the clarity of the learning objectives, the use of math representations and promoting mathematical concept development. "Who" domain includes teacher's attention to developmental trajectories, response students' individual needs and use of developmentally appropriate learning formats. The third HIS-EM domain, "How," reflects the teacher's ability to plan well organized math lessons, facilitate student engagement and establish math learning communities during the course of mathematics instruction.

The HIS-EM measures the extent to which these dimensions of quality teaching practices in early mathematics, both individually and collectively, are present in an observed lesson. Finally, dimensions are explained by various observable indicators. Each dimension consists of 3 to 4 indicators of high-impact instruction. For example, when determining a score for "Learning Objectives" dimension, the observer considers clarity of the learning objectives, their importance and relation to foundational math ideas, and whether they are built on prior knowledge. It is important to note that these indicators may not always present or equally significant in each lesson. In other words, the indicators under each dimension are not a check-list and observers evaluate dimensions holistically. Scores are assigned on a 7-points Likert scale categorized by low $(1,2)$, medium $(3,4,5)$, and high $(6,7)$ quality ratings.

The construct validity of the HIS-EM was established through an extensive literature review and consultation with experts in early math education. Reference to the NCTM standards and principles (2000) guided selection of the indicators for the HIS-EM. High levels of inter-rater reliability (.88) and internal consistencies (Cronbach's alpha .97) have been reported (Cerezci, 2016). Criterion-related validity of the HISEM was explored by examining the relationship between HIS-EM and the Classroom Assessment Scoring System (CLASS; Pianta, LaPora, \& Hamre, 2008), a global measure of instructional quality. The results suggested that CLASS domains and HIS-EM overall score were moderately correlated ( $r s=0.44$ to 0.58 ), with the strongest relationship between the HIS-EM overall score and the CLASS Instructional Support domain ( $\mathrm{r}$ $=0.58$ ). Only the CLASS "Instructional Support" domain average score had significant positive regression 
weights, indicating observed teachers with who have higher scores in this domain were expected to have higher HIS-EM scores, after controlling for the other variables in the model (i.e., "Emotional Support" and “Classroom Organization") (Cerezci, 2016).

\section{Procedures}

Trained observers conducted live in-class observations in the fall over the course of 8 w eeks at each participating school. One observation per classroom was planned. Each observation is considered a snapshot representing how mathematics instruction may function across a given school year. All of the observations were scheduled in advance in coordination with the participating teachers; and conducted during the time the teacher allocated to teach mathematics or the mathematics lesson time period. Scheduled observations were not specific to mathematical content (e.g., number and operations or geometry or etc.), or a particular instructional day (e.g., start or end of a weekly math unit). Observers remained in each classroom for the duration of the mathematics lesson.

\section{FINDINGS}

This study examined the kinds of teaching profiles exist among early childhood teachers as measured by HIS-EM. The investigation of the profiles of early childhood teachers' math teaching quality is done by analyzing; the distribution of HIS-EM scores across teachers, relationship between the HIS-EM domains and how they differed across teachers and whether there clusters of HIS-EM profiles betw een the teachers.

\section{The Distribution of HIS-EM Scores}

To investigate what kind of teaching profiles exist among early childhood teachers in terms of quality of teaching in early mathematics, pre-K to 3rd grade teachers were observed with HIS-EM (N=210) and their HIS-EM scores were analyzed. The average HIS-EM score (mean across nine dimensions) w as 4.06 (on a 1-7 scale; 1 being the lowest and 7 being the highest) and ranged from 1.67 to 6.78 , with a standard deviation of 1.24 . The medium level results partially supported the hypothesis that average quality of mathematics teaching $w$ as mediocre in early childhood settings.

Quality of mathematics teaching was further revealed by three domains of HIS-EM: "what" (foundational knowledge in mathematics), "who" (knowledge of young children), and "how" (effective use of instructional support). The score for each domain was determined by summing up the scores of its dimensions (e.g., "learning objectives," "mathematical representations," and "concept development" for "what" domain) and dividing it by three. As shown in the Table 1, the mean for the level of foundational knowledge in mathematics ("what") 4.04 ( $\mathrm{SD}=1.33$ ), knowledge of young children ("who") was 3.96 (SD=1.38), and effective use of instructional support ("how") was 4.05 ( $\mathrm{SD}=1.52)$ (See Table 1).

Table 1. Descriptive Statistics of HIS-EM Domains

\begin{tabular}{llll}
\hline & $\begin{array}{l}\text { What } \\
\text { (Foundational } \\
\text { Knowledge } \\
\text { Mathematics) }\end{array}$ & $\begin{array}{l}\text { Who } \\
\text { (Knowledge of }\end{array}$ & $\begin{array}{l}\text { How } \\
\text { Children) }\end{array}$ \\
\hline Mean (SD) & $4.04(1.33)$ & $3.96(1.38)$ & $\begin{array}{l}\text { (Effective Use of } \\
\text { Instructional Support) }\end{array}$ \\
Minimum & 1.33 & 1 & $1.05(1.52)$ \\
Maximum & 7 & 7 & 7 \\
Percentiles & 3.00 & & 2.67 \\
$25 \%$ & 4.00 & 2.67 & 4.00 \\
$50 \%$ & 5.00 & 4.00 & 5.00 \\
$75 \%$ & 5.00 & \\
\hline
\end{tabular}

Note: $N=210$ 


\section{The Relationship among the Domains of HIS-EM}

Correlational analysis was conducted to explore the relationship between the three domains of HISEM ("what," "who," and "how"). It was assumed that the three dimensions of HIS-EM are moderately correlated. A correlation coefficient - the extents to which two variables tend to change together - will be calculated and used to examine the relationships between HIS-EM domains. The coefficient describes both the strength and the direction of the relationship. The most commonly used correlation analyses, Pearson product moment correlation and Spearman rank-order correlation, were run for the purposes of this study by using correlational analyses. The Pearson correlation evaluates the linear relationship between two continuous variables (a change in one variable is a ssociated with a proportional change in the other variable) while the Spearman correlation evaluates the monotonic relationship between two continuous or ordinal variables (the change in variables is not necessarily proportional). Both correlation coefficients can range in value from -1 to +1 . The results suggested that there $w$ as a significant and positive relationship betw een the three domains of HIS-EM. The Pearson correlational coefficient (between .907 and .926, $\mathrm{p}<.001$ ) and Spearman correlations (between .906 and .926, p<.001) revealed similar strong correlations suggesting that foundational knowledge in mathematics, knowledge of students, and providing effective instructional strategies are intertwined with each other.

\section{The Comparisons among the Domains of HIS-EM}

A confirmatory factor analyses (CFA) was conducted with the HIS-EM data to test the three-factor model that assumes the 9 dimension reflect three, correlated underlying factors involving the HIS-EM domains of "What," "Who," and "How." The results revealed that the correlations among the What, Who, and How domains indicate that these three domains of HIS-EM are highly related ( $r s=0.98-0.99$ ) or largely overlapping in terms of what they measure. What and Who share $95.8 \%$ of their variance in comm on; What and How share $95.5 \%$ variance in common; and How and Who share $97.7 \%$ variance in common.

\section{Clusters of HIS-EM Profiles: Profiles of Early Childhood Teachers' Teaching Quality in Early Mathematics}

In order to investigate what kind of HIS-EM profile existed among the observed teachers, two-step cluster analysis was used to identify groups of teachers whose teaching showed similar levels or patterns. This analysis was run on the total sample (N=210) on three domains of HIS-EM ("what," "who," and "how"). Overall HIS-EM score was used as the evaluation factor. The results suggested that there were four uniquely profiled groups of teachers whose membership w as distributed in a reasonable manner with $15.7 \%$, in cluster $1,21 \%$ in cluster $2,35.7 \%$ in cluster 3 , and $27.7 \%$ in cluster 4 . The summary of the cluster model, including a silhouette measure of cluster cohesion and separation, revealed a strong evidence of cluster structure (the silhouette measure average > .5) (Kaufman \& Rousseeuw , 1990) regarding interpretation of cluster structures. Based on the profiles to be discussed, the clusters were named as follows: Cluster 1 as" low," Cluster 2 as "mid-low," Cluster 3 as "medium," and Cluster 4 as "high." 58 teachers out of 210 (27.6\%) were in Cluster 1, featured by "low" level of quality of mathematics teaching; 75 teachers $(35.7 \%)$ in Cluster 2, characterized by a "mid-low" level of foundational knowledge in mathematics; 44 teachers (\% 21) in Cluster 3, grouped by a "medium" level of know ledge of young children; and only 33 teachers (15.7\%) were in Cluster 4 with "high" levels of effective use of instructional support. Overall, the two-step cluster analysis revealed that teachers did have different HIS-EM profiles in regards to the quality of early mathematics teaching they provided. There was only a small portion of the teachers whose HIS-EM scores were higher than that of most of the teachers in the sample (approximately 15\%).

\section{RESULT, DISCUSSION, AND SUGGESTIONS}

The primary aim of this research was to analyze the quality of early mathematics instruction during the course of mathematics teaching to understand what kind of mathematics teaching profiles exist among early childhood teachers (preschool to 3rd grade). The descriptive results revealed that the quality of mathematics instruction varies considerably among early childhood teachers. Some teachers are identified as delivering high quality mathematics instruction because they provide students with opportunities to fully 
and purposefully engage in deepening their understanding of important mathematics concepts, whereas others are rated as far lower in quality, because their mathematics teaching is very procedural in terms of content emphasized and instructional strategies used. In such situation, learning conceptual mathematics was unlikely, if not impossible. As a whole, observed quality of mathematics teaching was revealed to be mediocre. That is, teachers displayed rather basic knowledge of foundational mathem atics concepts (i.e., what), limited understanding of young children's typical learning pathways in mathematics and diverse students' learning needs (i.e., who), and occasional use of instructional support (i.e., how).

\section{The "What" of Quality Mathematics Teaching: Knowledge of Foundational Mathematics Concepts}

More than anything else, the literature on mathematics instruction indicates that having a sound understanding of mathematics plays a crucial role in early childhood teachers' ability to communicate mathematics concepts in a meaningful way and to help children make connections and develop their own mathematical ideas (Ball, Lubienski, \& Mewborn, 2001; Ma, 1999; Copley, 2004; Ginsburg et al., 2008; Rudd et al., 2008). However how sound mathematics know ledge can be evidenced in mathematics instruction during the course of early mathematics teaching has often been overlooked and is not well studied, especially in early childhood classrooms. The current study investigated the quality of early childhood teachers' knowledge of foundational mathematics concepts and how it surfaces over the course of mathematics teaching as measured through the "what" domain of HIS-EM. Unfortunately, too few children are exposed to these types of high quality mathematics instruction throughout the early grades. Early childhood teachers in the sample did not demonstrate adequate levels of foundational understanding for high quality mathematics teaching. The mean score for the "what" domain was 4.04 out of 7 , and about $85 \%$ of the teachers were equal to or below the medium level of understanding, indicating that the majority of the teachers appeared to have basic content knowledge. Although the majority of teachers addressed important mathematics content, more often than not, they failed (1) to incorporate "Big Ideas" of mathematics into their lessons effectively, (2) to articulate connections between mathematical concepts and tools in a way that enabled students to investigate and connect mathematical concepts, and (3) to clarify students' misconceptions in a way that guided them tow ards a deeper understanding of the concept under discussion. Furthermore, the classroom observations showed that some early childhood teachers in the study focused largely on students' recitative skills in their lessons. They asked students to rote count up to a certain number. Even when they used manipulatives such as unifix cubes to help children stay on track while counting, the teachers failed to help some students use them productively, including correctly using number words in sequence and connecting each number word to one object in order. In other lessons, students spent most of the time playing a mathematics-related game but teachers paid scant attention to the mathematics concepts embedded in the game. Some lessons focused on completing worksheets with no articulation of how the lesson topic was connected to important mathematical concepts. In one case, teacher guided students through the completion of a math worksheet by referring the students to a particular question, telling them to turn to a specific page in their textbook and look for the answer, asking students to read the answer from the book, and then writing the answer on the board. In all these incidences, although teachers set learning goals, these goals were procedural rather than conceptual. The materials provided students with limited opportunities to engage in math learning. Altogether, this level of teaching would lead students tow ard only partial understanding of mathematical concepts.

\section{The "Who" of Quality Teaching: Knowledge of Young Children}

Many early childhood development and education experts emphasize the vital importance of early childhood teachers' familiarity with how young children develop and learn in order to better scaffold the learning process for the child (Vygotsky 1978). Ideally, instruction should correspond with students' development; if the students are actually to learn what is instructed, attention will have to be paid to 
whether students' instructional experiences are aligned with the trajectory of students' thinking and learning (Clements \& Sarama, 2007). Although researchers have described the developmental trajectories and learning progressions for math contents and concepts (Clements \& Sarama, 2004; Sar ama \& Clements, 2004), the degree to which instruction reflects an understanding of young children's development and individual students' learning needs in mathematics is often overlooked and understudied.

The current study examined teachers' understanding of young children ("who" domain of HIS-EM) in terms of their ability to assess what an individual student knows or needs to know about a particular concept and provide scaffolding accordingly, and to use variety of modalities to gain students' interest to further conceptual understanding and learning.

Unfortunately, few children in the present study were exposed to types of early mathematics instruction that correspond with their development and learning. According to the results, early childhood teachers in the study displayed limited levels of understanding regarding how young children approach mathematics and how their mathematics learning can be supported developmentally. Specifically, the mean for "who" domain was 3.96 and about $85 \%$ were equal or below the medium level of understanding. Most teachers displayed limited knowledge of the developmental trajectory for the mathematical topic they are teaching and provided some scaffolding that tends to focus on getting the "right" answer and not on building students' understanding. Although many of the lessons observed were taught in appropriate instructional grouping with an appropriate pacing, they were unfortunately not very productive.

For example, in one lesson the teacher in a 2nd grade classroom used "fill-in-the-blank" questions as a way to "scaffold" students' learning with an emphasis on getting the right answer. The students were asked to find the right numbers (which numbers to subtract from which number) without connecting these procedures to any meaning. The mathematical content was developmentally appropriate but scaffolding was superficial and the learning format of the lesson emphasized the "completed work" with little concern for evidence or understanding the concept of "taking away."

According to the "who" domain, teachers also need to understand how individual students learn and how to differentiate their teaching in order to meet the mathematical needs of all students and ensure that no students slip between the cracks. HIS-EM observations revealed that most of the observed teachers displayed knowledge of some of their students' skills and conceptual understandings but not of them. Some of the students were even "left out" of the lesson. For example, in one of the lessons, though the teach er had realized a few students in her small group were not able to recognize numerals higher than 10, no effort was observed during the class to engage them in a way diverging from the techniques used for the rest of the students.

\section{The "How" of Quality Teaching: Effective Use of Instructional Support}

On a daily basis, teachers make an abundance of instructional decisions that can either discourage or promote a supportive environment for mathematics learning. In order to effectively develop students' mathematical skills, teachers also need to provide effective instructional support in mathematics. For example, research has demonstrated that student achievement is higher in classes where instructional time is maximized through careful planning (Walberg, 1984). Research also indicates that teachers' questions are crucial in helping students make connections and learn mathematics concepts (Sutton \& Krueger, 2002) and promoting a sense of mathematical learning communities (Ball, 1991; Cobb, Yackel, Wood, \& Wheatley, 1988) by communicating high expectations for all students and encouraging them to share their ideas and solutions about given problems, are all procedures which are key to quality mathematics teaching.

The current study defined understanding of instructional methods and effective use of instructional support ("how" domain of HIS-EM) in terms of how the teachers interweave the math content and its accompanying pedagogy by planning coherent and conceptual math lessons, engaging children in purposeful ma thematical 
reasoning and inquiry, and fostering a positive disposition towards mathematics during the course of mathematics instruction.

Unfortunately, early childhood teachers in this study displayed limited use of instructional methods. The mean for "how" domain was 4.05 and about $85 \%$ were equal or below the medium level of understanding. Most teachers (1) planned activities that focused on procedures with some connections to underlying mathematical concepts, (2) failed to use questioning effectively to find out what students already know or do not know about a concept addressed to provoke deeper thinking, and (3) occasionally offered encouragement of students' efforts that increases mathematical discussion and risk-taking in sharing ideas.

In general, teachers seemed to struggle to find the balance between establishing a mathematics learning community that encourages students to generate ideas and questions and express their mathematical ideas honestly and openly, and planning pleasant but rigorous math activities. For example, in one of the lessons, the teacher showed genuine enthusiasm for mathematics and had a warm relationship with the students. In terms of mathematical intellectuality however, the mathematical learning community in this classroom w as barely existent. Mathematics w as presented as combinations of facts and formulas that needed to be memorized by rote. Students rarely received encouragement to share their mathematical ideas with the rest of the students. In some of the other lessons, students were criticized for giving wrong responses. Such a response from the teacher might create a rather hostile learning environment in which it was not acceptable to be wrong while responding to and engaging in the mathematics lesson. Also, the teachers mostly tended to ask closed questions in lessons, tending to evoke only yes/no or "fill- in-the-blank" responses from students. The problem with these closed questions is that it is often difficult to tell if students conceptually understand the content or not and even if they do so, it is still unclear whether others in the class possess a similar level of understanding.

\section{Variation of Quality in Early Mathematics Instruction}

The findings of the study also revealed that most of the observed lessons failed to provide high quality learning experiences in mathematics to all students. As two-step cluster analysis results suggested only about 15 percent of the Pre-K to 3rd mathematics lessons were classified as high quality, while about 21 percent were medium, 38 percent were medium-low, and 23 percent were low. These results mirrored the results of the Inside Classroom study in which the researchers observed and rated about 360 math ematics lessons in $\mathrm{K}$ to 12 and found dramatic variances in the quality of mathematics teaching provided (Weiss, Pasley, Smith, Banilower, \& Heck, 2003). More specifically, the researchers suggested that more than half of the observed lesson was considered as low in quality while only 15 percent was high and 27 percent was medium in quality (Weiss, Pasley, Smith, Banilower, \& Heck, 2003).

As mentioned previously, three domains of HIS-EM (i.e., what, who, and how) seemed to collectively influence the extent to which the overall quality of mathematics instruction can be enacted during the course of observed mathematics lessons. Consistently, examination of varying degrees of mathematics teaching quality in observed lessons also indicated that how well the teachers show case the what, who, and how of mathematics teaching as reflected by HIS-EM depends on how well the teacher demonstrated the desirable features of each HIS-EM domain during the course of early mathematics teaching. For example, mathematics instructions of the teachers who were identified as high quality as measured by HIS-EM simultaneously reflected and sheltered the elements of foundational and conceptual mathematics content (Bransford, Brown \& Cocking, 1999; Hamre \& Pianta, 2007; Stein, Smith, Hen ningsen \& Silver, 2009), a high level of expertise in understanding how students learn and think about the concepts related to the content that being taught (Emmer \& Stough, 2001; Cameron, Connor \& Morrison, 2005) and high levels of instructional support in helping students develop an understanding of the mathematical content by providing a challenging yet supportivelearning environment (Yackel \& Cobb, 1996). On the other hand, low quality mathematics instruction appeared to be lacking intentionality in di recting and designing 
interactions between the content and students. In particular, teachers were not familiar with either the content or its accompanying pedagogy and failed to appropriately challenge, scaffold and extend students' mathematics knowledge and skills in mathematics.

\section{Limitations and Future Directions}

First, the current study involves a sample of public schools specifically catering to the teachers who are working with students from low-income families. Therefore, it is unclear whether the results can be generalized to different populations. Though developed for use across any early childhood setting, it is impossible to discern the extent to which the HIS-EM may be applicable for settings unrepresented in the current sample, such as private schools and licensed daycare centers. Second, the fact that all teachers in this study are highly educated and certified to teach in early childhood classrooms limits the generalizability of the findings to other less credentialed early childhood teachers. Future research should examine the applicability of the HIS-EM in wider array of early childhood classrooms with greater diversity at both child and teacher level. Third, all HIS-EM data was collected in single-day observations in each teacher's classroom. Unfortunately, single-day observations may not necessarily reflect teacher practice across the entire school year. Synthesis of multiple observation cycles could reveal the true portray of early mathematics teaching happening in our classrooms. Future research should also examine how multiple observations within a short timeframe impacts the reliability of the estimates of quality of mathematics instruction. For example, most of the curriculums used in the school settings are often organized in units, which tend to change bi-w eekly, if not w eekly. By observing and documenting multiple mathematics lessons across consecutive days within a single school week or two weeks, researchers can gain a more comprehensive understanding of mathematics instruction and therefore may be able to measure quality mathematics instruction more reliably. Last but not least, this study presents descriptive data on the quality of early mathematics teaching as measured by HIS-EM instrument, however it does not examine teaching quality and early mathematics teaching profiles in relation to student outcomes. Therefore, future studies should be conducted to analyze the predictive qualities of this measure.

\section{REFERENCES}

Armstrong, A., Ginet, L., \& Warisi, S. (2012, January). Exploring early math teaching and learning in community college ECE programs. Poster session presented at the annual meeting of the Illinois Education Research Council, Tinley Park, IL.

Aunola, K., Leskinen, E., Lerkkanen, M. K., \& Nurmi, J. E. (2004). Developmental dynamics of math performance from preschool to grade 2. Journal of Educational Psychology, 96(4), 699-713.

Ball, D. L. (1990). The mathematical understandings that prospective teachers bring to teacher education. The Elementary School Journal, 90(4), 449-466.

Ball, D. L. (1991). What's all this talk about "discourse"? Arithmetic Teacher, 39(3), 44-48.

Ball, D. L., \& Row an, B. (2004). Introduction: Measuring instruction. Elementary School Journal, 105(1), 3-10.

Baroody, A.J. (2001). Early number instruction. Teaching Children Mathematics, 8(3), 154-158.

Baroody, A. J., \& Dowker, A. (2003). The development of arithmetic concepts and skills: Constructing adaptive expertise. Mahwah, NJ: Erlbaum.

Bodovski, K \& Farkas, G. (2007) Mathematics Growth in Early Elementary School: The Roles of Beginning Knowledge, Student Engagement and Instruction. The Elementary School Journal, 108(2), 115-130.

Bransford, J., Darling-Hammond, L., \& LePage, P. (2005). Introduction. In L. Darling- Hammond and J. Bransford (Eds.). Preparing teachers for a changing world: What teachers should learn and be able to do (pp. (1-39). San Francisco: Jossey- Bass. 
Brenneman, K., Boller, K., Atkins-Burnett, S., Stipek, D., Forry, N., Ertle, B., French, L., Ginsburg, H., Frede, E. \& Schultz T. (2011). Measuring the quality of early childhood math and science curricula and teaching. In M Zaslow, I. Martinez-Beck, K. Tout \& T. Halle (Eds.), Quality Measurement in Early Childhood Settings (pp.77-103). Baltimore Maryland: Paul H. Brookes Publishing Co.

Brophy, J. E. (1991). Conclusion to advances in research on teaching, Vol. II: Teachers' knowledge of subject matter as it relates to teaching practice. In Brophy (Ed.), Advances in research on teaching: Vol. 2 Teachers' subject matter knowledge and classroom instruction (pp. 347-362). Greenwich, CT: JIA Press.

Brown, E. T. (2005). The influence of teachers' efficacy and beliefs regarding mathematics instruction in the early childhood classroom. Journal of Early Childhood Teacher Education, 26, 239-257.

Bursal, M. \& Paznokas, L. (2006). Mathematics anxiety and preservice elementary teachers' confidence to teach mathematics and science. School Science and Mathematics, 106(4), 173-180.

Cameron, C. E., Connor, C. M., \& Morrison, F. J. (2005). Effects of variation in teacher organization on classroom functioning. Journal of School Psychology, 43, 61-85.

Carr, M., Peters, S. \& Young-Loveridge, J. (1994). Early Childhood Mathematics - A Framework. In J. Neyland (Ed.) Mathematics Education -A Handbook for Teacher. Vol 1, pp.262-269. Wellington: Wellington College of Education.

Chung, K.-E. (1994). Young children's acquisition of mathematical knowledge and mathematics education in kindergarten. Unpublished doctoral dissertation, Iow a State University, Iow a.

Clements, D.H. (2001). Mathematics in the preschool. Teaching Children Mathematics, 7, 270-275.

Clements, D. H. (2004). Preface. In D. H. Clements, J. Sarama, \& A. -M. DiBiase (Eds.), Engaging young children in mathematics: Standards for early childhood mathematics education (pp. ix-xv). Mahwah: Law rence Erlbaum.

Clements, D. H., \& Sarama, J. (2007). Effects of a preschool mathematics curriculum: Summative research on the Building Blocks project. Journal for Research in Mathematics Education, 38, 136-163.

Clements, D. H. \& Sarama, J. (2009). Learning and teaching early math: The learning trajectories approach. New York, NY: Routledge.

Clements, D. H., \& Sarama, J. (2011). Early childhood mathematics intervention. Science, 333(6045), 968-970.

Clements, D. H., Sarama, J., \& Gerber, S. (2005, April). Mathematics Knowledge of Entering Preschoolers. Paper presented at the Annual Meeting of the American Educational Research Association, Montreal, Canada.

Cobb, P., Yackel, E., Wood, T., \& Wheatley, G. (1988). Research into practice: Creating a problem-solving atmosphere. Arithmetic Teacher, 36(1), 46-47.

Copley, J. V., (2004). The early childhood collaborative: A professional development model to communicate and implement the standards. In D. H. Clements, J. Sarama, \& A.-M., DiBiase (Eds.), Engaging young children in mathematics: Standards for early childhood mathematics education (pp. 401-414). Mahwah: Law rence Erlbaum.

Copple, C. E. (2004). Mathematics curriculum in the early childhood context. In D. H. Clements, J. Sarama, \& A.-M., DiBiase (Eds.), Engaging young children in mathematics: Standards for early childhood mathematics education. Mahwah: Law rence Erlbaum.

Darling-Hammnod, L. (2006). Constucting 21 ${ }^{\text {st }}$ Century Teacher Education. Journal of Teacher Education, Vol. $57(10), 1-15$.

Duncan, G. J., Dowsett, C. J., Claessens, A., Magnuson, K., Huston, A. C., Klebanov, P., et al. (2007). School readiness and later achievement. Developmental Psychology, 43, 1428-1446.

Emmer, E. T., \& Stough, L. M. (2001). Classroom management: A critical part of educational psychology, with implications for teacher education. Educational Psychologist, 36(2), 102-112. 
Engel, M., Claessens, A., \& Finch, M. (2011). Teaching students what they already know? The misalignment between mathematics instructional content and student knowledge in kindergarten. Paper presented at the American Educational Research Association Annual Meeting, New Orleans, Louisiana.

Epstein, A. S. (2003). How planning and reflection develop young children's thinking skills. Young Children, 58(4), 28-36.

Fennema, E. \& Romberg, T. A. (Eds.) (1999). Classrooms that promote mathematical understanding. Mahwah, NJ: Erlbaum.

Flanagan, K.D., McPhee, C., \& Mulligan, G. (2009). The Children Born in 2001 at Kindergarten Entry: First Findings From the Kindergarten Data Collections of the Early Childhood Longitudinal Study, Birth Cohort (ECLS-B). (NCES 2010-005). Washington, DC: National Center for Education Statistics.

Ginsburg, H. P., Jang, S., Preston, M., Appel, A., \& VanEsselstyn, D. (2004). Learning to think about early childhood mathematics education: A course. In C. Greenes \& J. Tsankova (Eds.), Challenging young children mathematically (pp. 40-56). Boston, MA: Houghton Mifflin.

Ginsburg, H., Lee, J., \& Byod, J. (2008). Mathematics education for young children: What it is and how to promote it. Society for Research in Child Development, Social Policy Report, 22, 3-22.

Graham, T.A., Nash, C., \& Paul, K. (1997). Young children's exposure to mathematics: The child care context. Early Childhood Education Journal, 25(1), 31-38.

Hill, H.C., Schilling, S.G., \& Ball, D.L. (2004) Developing measures of teachers' mathematics knowledge for teaching. Elementary School Journal, 105, 11-30.

Kilpatrick, J., Swafford, J., \& Findell, B. (Eds.). (2001). Adding it up: Helping children learn mathematics. Washington, DC: National Academy Press.

Klein, A., \& Starkey, P. (2004). Fostering preschool children's mathematical knowledge: Findings from the Berkeley Math Readiness Project. In D. H. Clements \& J. Sarama (Eds.), Engaging young children in mathematics (pp. 343-360). Mahwah, NJ: Erlbaum.

Lee, J. S. (2004). Correlations between kindergarten teachers' attitudes toward mathematics and teaching practice. Journal of Early Childhood Teacher Education, 25(2), 173-184.

Lee, J. S., Ginsburg, H. (2009). Early childhood teachers' misconceptions about mathematics education for young children in the United States. Australasian Journal of Early Childhood, 34(4), 37-45.

Ma, L. (1999). Knowing and teaching elementary mathematics. Mahwah, NJ: Law rence Erlbaum Associates, Publishers.

National Association for the Education of Young Children and National Council of Teacher s of Mathematics. (NAEYC \& NCTM) (2002). Early childhood mathematics: Promoting good beginnings. Retrieved from http://www. naeyc.org/about/positions/psmath.asp

National Commission on Mathematics \& Science Teaching for the 21st Century. (NCMST) (2000). Before it's too late: A report to the Nation from the National Commission on Mathematics and Science Teaching for the 21st Century.

National Research Council. (2009). Mathematics in early childhood: Learning paths toward excellence and equity. Washington, DC: National Academy Press.

Organization for Economic Cooperation and Development (OECD) (2012). Education at a Glance 2012: Highlights, OECD Publishing.

Pianta, R. C., LaParo, K. M., \& Hamre, B. K. (2008). Classroom Assessment Scoring System (CLASS) Pre-K Version. Baltimore, MD: Brookes Publishing.

Richardson, K., \& Salkeld, L. (1995). Transforming mathematics curriculum. In Sue Bredekamp \& Teresa Rosegrant (Eds.), Reaching potentials: Transforming early childhood curriculum and assessment (Vol. 2, pp. 23-42). Washington, DC: National Association for the Education of Young Children. 
Rivkin, S. G., Hanushek, E. A., \& Kain, J. F. (2005). Teachers, schools, and academic achievement. Econometrica, 73(2), 417-458.

Romberg, T., \& Kaput, J. (1999). Mathematics worth teaching, mathematics worth understanding. In E. Fennema, \& T. Romberg (Eds.), Mathematics classrooms that promote understanding (pp. 3-18). Mahwah, NJ: Law rence Erlbaum Associates.

Rudd, L. C., Lambert, M. C., Satterwhite, M., \& Zaier, A. (2008). Mathematical Language in Early Childhood Settings: What Really Counts? Early Childhood Education Journal, 36, 75-80.

Sanders, W. L., \& Rivers, J. C. (1996). Cumulative and residual effects of teachers on future student academic achievement. Knoxville, TN: University of Tennessee Value-Added Research and Assessment Center.

Sarama, J., \& Clements, D. H. (2010). The mathematical lives of young children. In V. Washington \& J. D. Andrew (Eds.), Children of 2020: Creating a better tomorrow (pp. 81-84). Washington, DC: Council for Professional Recognition.

Sarama, J., Di Biase, A.M., Clements, D. H.,\& Spitler, M. E.(2004).The Professional Development Challenge in Preschool Mathematics. In D. H. Clements, J. Sarama, \& A.M. DiBiase (Eds.), Engaging Young Children in Mathematics: Standards for Early Childhood Mathematics Education (pp. 415-446). Mahw ah, NJ: Law rence Erlbaum Associates Publishers.

Saxe, G. B., Guberman, S. R., \& Gearhart, M. (1987). Social processes in early number development. Monographs of the Society for Research in Child Development, 52(2, Serial No. 216).

Starkey, P., Klein, A. and Wakeley, A. (2004) Enhancing Young Children's Mathematical Knowledge through a Pre-Kindergarten Mathematics Intervention. Early Childhood Research Quarterly, 19(1), 99-120.

Starkey P, Klein A, DeFlorio L. (2014). Promoting math readiness through a sustainable prekindergarten mathematics intervention. In: Boivin M, Bierman KL, eds. Promoting school readiness and early learning. Implications of developmental research for practice. New York, NY: The Guilford Press; 2014:187-210.

Stein, M. K., Smith, M. S., Henningsen, M. A., \& Silver, E. A. (2009). Implementing standards-based mathematics instruction: A casebook for professional development (Second Edition). New York, NY: Teachers College Press.

Sutton, J., \& Krueger, A. (Eds). (2002). EDThoughts: What we know about mathematics teaching and learning. Aurora, CO: Mid-Continent Research for Education and Learning.

Tudge, J., \& Doucet, F. (2004). Early mathematical experiences: Observing young Black and White children's everyday experiences. Early Childhood Research Quarterly, 19, 21-39.

Van Den Heuvel-Panhuizen, M. (1990). 'Realistic arithmetic/mathematic instruction and tests' in: Gravemeijer, K., Van den Heuvel, M. \& L. Streefland, L. (eds) Contexts, Free Productions, Tests and Geometry in Realistic Mathematics Education, State University of Utrecht, The Netherlands, OW\&OC, pp. 53 - 78.

Vygotsky, L. S. (1978). Mind in society: The development of higher psychological processes (Michael Cole, Vera John-Steiner, Sylvia Scribner, \& Ellen Souberman, Eds. \& Trans.). Cambridge, MA: Harvard University Press.

Walberg, H. J. (1984). Improving the productivity of America's schools. Educational Leadership, 41(8), 19-27.

Weiss, I. R. \& Pasley, J. D. (2004). What is high-quality instruction? Educational Leadership, 61(5).

Weiss, I. R., Pasley, J. D., Smith, P. S., Banilower, E. R., \& Heck, D. J. (2003). Looking inside the classroom: A study of K-12 mathematics and science education in the United States. Chapel Hill, NC: Horizon Research, Inc. 
Cerezci,B. (2019). Early mathematics teaching profiles. International Journal of Educational Research Review,4(3),288-302.

Wilkins, J.L.M. (2008). The relationship among elementary teachers' content knowledge, attitudes, beliefs, and practices. Journal of Mathematics Teacher Education, 11 (2), 139-164.

Yackel, E. and Cobb, P. (1996) Sociomathematical norms, argumentation, and autonomy in mathematics. Journal for Research in Mathematics Education, 22, 390-408. 